低温化打引る比熱測定は技術的にみると, $20^{\circ} \mathrm{K}$ 以 上, $20^{\circ} \mathrm{K} \sim 1^{\circ} \mathrm{K}, 1^{\circ} \mathrm{K}$ 以下以大別出来る。更任 $1^{\circ} \mathrm{K}$ 以下は $\mathrm{He}^{3}$ 営用いる $0.5 \sim 0.3^{\circ} \mathrm{K}$ までの領域と, 断

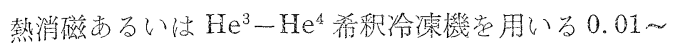
$0.001^{\circ} \mathrm{K}$ までの領域に分けて考光るととが出来る。 $1^{\circ} \mathrm{K}$ 以上のいわ的 $\mathrm{He}^{4}$ 温度領域での比熱測定につ いては，すでに畫いているので1〕てでは $1^{\circ} \mathrm{K}$ 以下 の場合特に断熱消磁, $\mathrm{He}^{3}-\mathrm{He}^{4}$ 希釈冷湅機老用いる 場合の比熱測定について書くととにする。この分野は 我々が現在とりかかっているもので, ほとんど未経験 のため, 先達によって作り上げられた技術の紹介飞終 始せざる老得ないとと者断って招をたい。

$1^{\circ} \mathrm{K}$ 以下の此熱測定は, 主として二つの分野に和い て行なわれ技術開発がなされて来た。その一つは金属 試料特に超伝導体の比熱測定であり, 他の一つ液体 $\mathrm{He}^{3}$ の比熱測定である。前者は主に N.E. Phillips に よるもので測定最低温度は $0.1 \sim 0.08^{\circ} \mathrm{K}$ で西る。後 者は近年特に J.C. Wheatley 達によって開発され 4 $\sim 6 \mathrm{~m}^{\circ} \mathrm{K}\left(1 \mathrm{~m}^{\circ} \mathrm{K} \equiv 0.001^{\circ} \mathrm{K}\right)$ まで測定がなされている。 良く知られているよう亿, 低温比熱測定の根幹在な すものは，クライオスタットと温度計とである。クラ イオスタットは如何にして試料堂冷却するかというて とと如何にして試料老断熱状態にするかというととの 二点からまず考光られるべきもので市るが，使い易 さというととも大变重要な要素である。ととではいく つかの代表的なクライオスタット支紹介するが, 実際 の作成の祭には各自の測定刘象和上び測定温度領域に よって適当に取捨選択, 改良をされればよい。温度計 については, セリウム・マグネシウム・ナイトレイト $2 \mathrm{Ce}\left(\mathrm{NO}_{3}\right)_{3} \cdot 3 \mathrm{Mg}\left(\mathrm{NO}_{3}\right)_{2} \cdot 24 \mathrm{H}_{2} \mathrm{O}$ (略して $\mathrm{CMN}$ ) ついての最近の話題を紹介する。

\section{Phillips のクライオスタット2)}

彼のクライオスタット丵図1亿示す。

$*$ 東北大学理学部

Vol. 4 No. 4 (1969) (i) 測定温度範国

$$
0.08 \sim 1.1^{\circ} \mathrm{K}
$$

(ii) 冷却塩

$\mathrm{CuSO}_{4} \cdot \mathrm{K}_{2} \mathrm{SO}_{4} \cdot 6 \mathrm{H}_{2} \mathrm{O}$, 使用量 $200 \mathrm{~g}$

粉末を薄い銅板に压しつけて型をつくる。

(iii) プロセス

塩打よび試料は室温から $1.1 \circ \mathrm{K}$ まで機械的熱スイ ッチを閉して行なう（スイッチにかける力約 $4.5 \mathrm{~kg}$ )。

$1.1^{\circ} \mathrm{K}$ にて外磁場をかけ, 磁化熱を奪い去るのに約 30分要する。次に機械的熱スイッチを開き, 率熱消磁

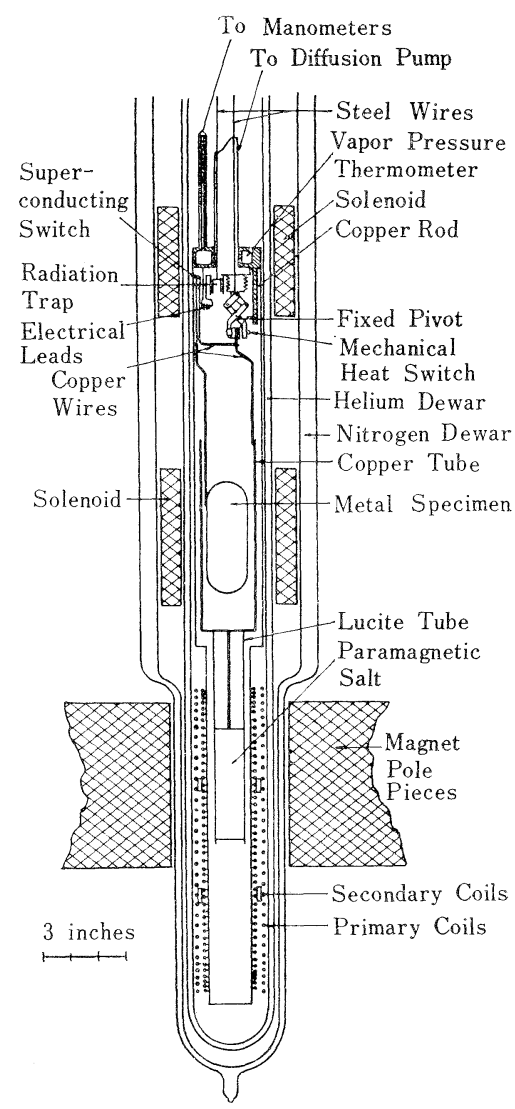

(a) 初期のもの 


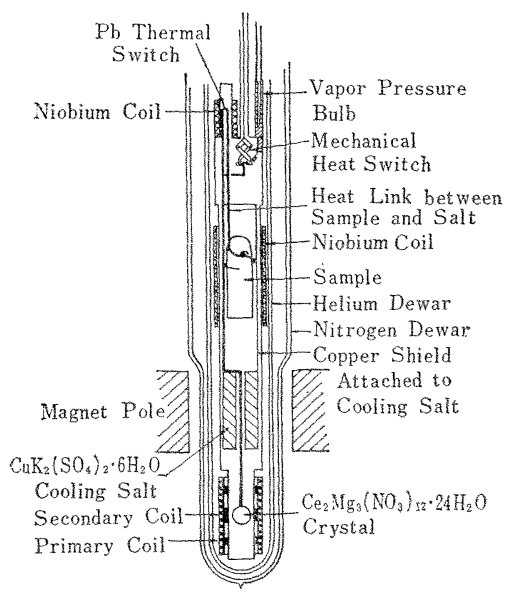

(b) 改 喪 型

図 1 N.E. Phillips のクライオスタット

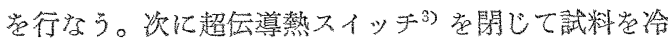
却し, 試料方最低温度に達したら超伀導スイッチを開 き，試料怘断熱状態にしたのち比熱湘定落行なう。 (iv) その地

ヒーターとしてマンガニン線学用いている。そして

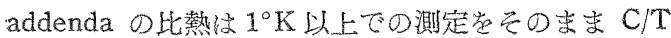
一、T和ロットで外插して差し引いている。マンガニ ン線は $0.5^{\circ} \mathrm{K}$ あだ加ら $1 / \mathrm{T}^{2}$ の核比熱走示劣 でこの外㨀は愦美崖生しる。

塩を冷却するのに譏械的熱スイッギを用いると, へ リウム交換ガスの脱着がないので，1K附近でのデー 夕栄精確に得るととが出来方利点がある。

\section{Ancsin のクライオスタット5)}

彼のクライオスタット芭図2亿示す。

(i) 湘定温度範囲

$$
0.2 \sim 5^{\circ} \mathrm{K}
$$

(ii) 玲却笽

$\mathrm{Cr}_{2}\left(\mathrm{SO}_{4}\right)_{2} \cdot \mathrm{K}_{2} \mathrm{SO}_{4} \cdot 24 \mathrm{H}_{2} \mathrm{O}$ 使用量75 $\mathrm{g}$

粉末をブチル・フタレイトと混ぜて，銅筒の中につ

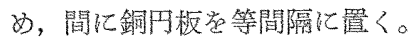

(iii) プロセス

最初七ルの中に窒素ガス岩入れ，室温から液体窒素 温度まで椧却する(約2 時間要する)。

次に窒素ガス老排気したのち液体へリウム亚波多,

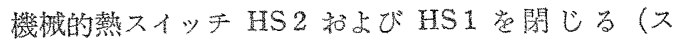

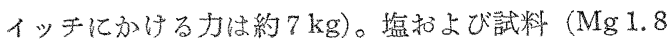

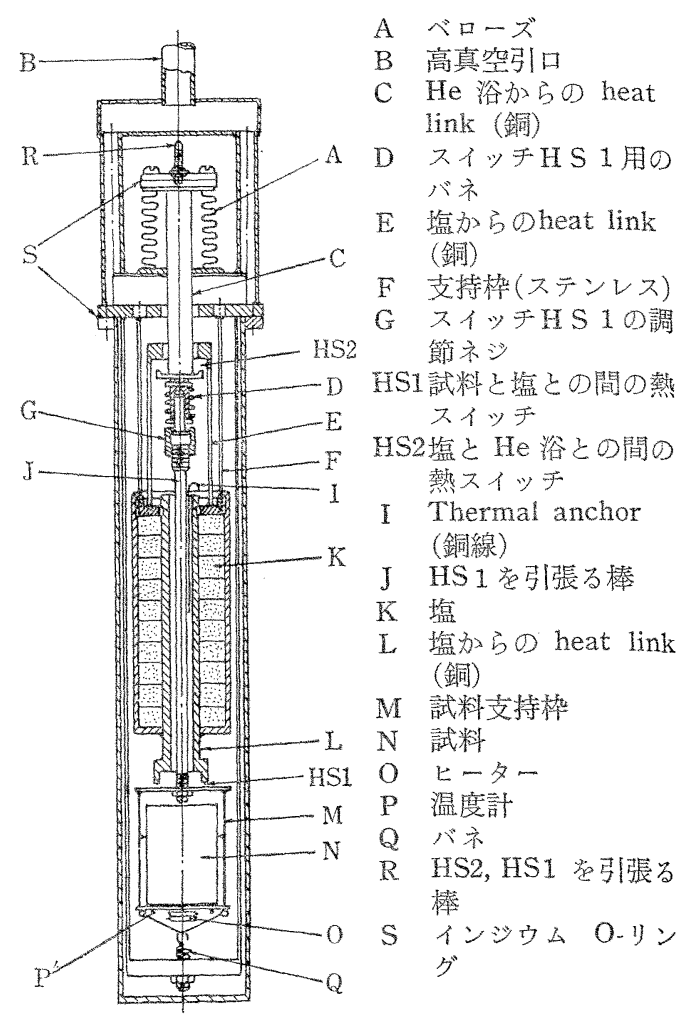

図 2 J.Ancsin のクライオスタット

モル）が $4.2^{\circ} \mathrm{K}$ に冷光るまで約3 時間要する。

$4.2^{\circ} \mathrm{K}$ 加ら $1.3^{\circ} \mathrm{K}$ 富で泠えるのに約 30 分でよ Wo

$1.3^{\circ} \mathrm{K}$ 儿て外磁場学加引(約18 kG) 磁化熱学奪い さるのに, 約 1 時間半要する。

次化 HS2 在開いて断熱消磁点行なう。20分かけ て断熱消磁老行なうと, 試料加 $1.3^{\circ} \mathrm{K}$ 加方 $0.15^{\circ} \mathrm{K}$

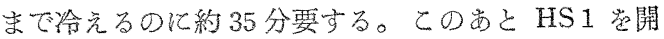
いて試料老断熱状態にして比熱測定学行なう。

(iv) その优

HS 1 蝉開いた際，試料の温度は $0.03^{\circ} \mathrm{K}$ 程上昇す る。 Mg についての実祭の測定デー夕が示されていな いので，信用度は焦いと考えざる学得ない。

\section{3. $\mathrm{He}^{3}-\mathrm{He}^{4}$ 希䣋冷渲機を用いたクライ オスタッド） (Daybel-Steyert)}

彼らか用いているクライオスタット觉図 3 亿示す。 $\mathrm{He}^{3}$ - $\mathrm{He}^{4}$ 希秋冷凍機については文献觉参照された (7)。

(i) 测定温度領域 


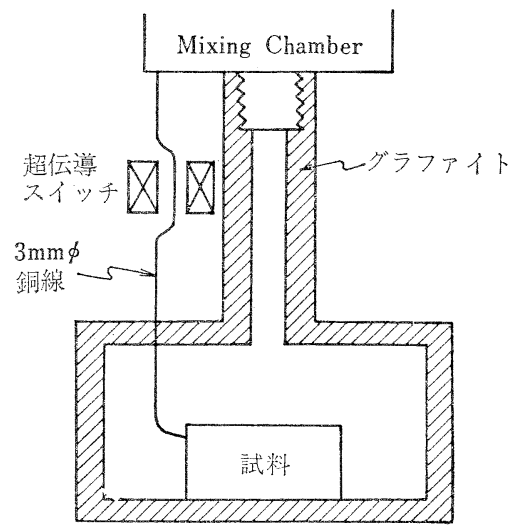

图 $3 \mathrm{He}^{3}$ - $\mathrm{He}^{4}$ 希釈冷凍機老用いた Daybel一 Steyertのクライオスタット

$0.04 \sim 1.0^{\circ} \mathrm{K}$

(ii) ヒーター

$0.2^{\circ} \mathrm{K}$ 以上ではマンガニン線学使用。

$0.35^{\circ} \mathrm{K}$ 以下では， $\gamma$-線 $\left(\mathrm{Co}^{60} 20 \mathrm{mCi}\right)$ 串用い， ケ線による加熱は， $0.2 \sim 0.35^{\circ} \mathrm{K}$ でのマンガニン線 による加熱により較正する。

(iii) 試料支持台

$0.04^{\circ} \mathrm{K}$ 程度になると，金属試料の比熱は非常に小 さくなるため，振動による温度上昇学防ぐことが最も 重要になる。このために試料をグラファイト支持台に

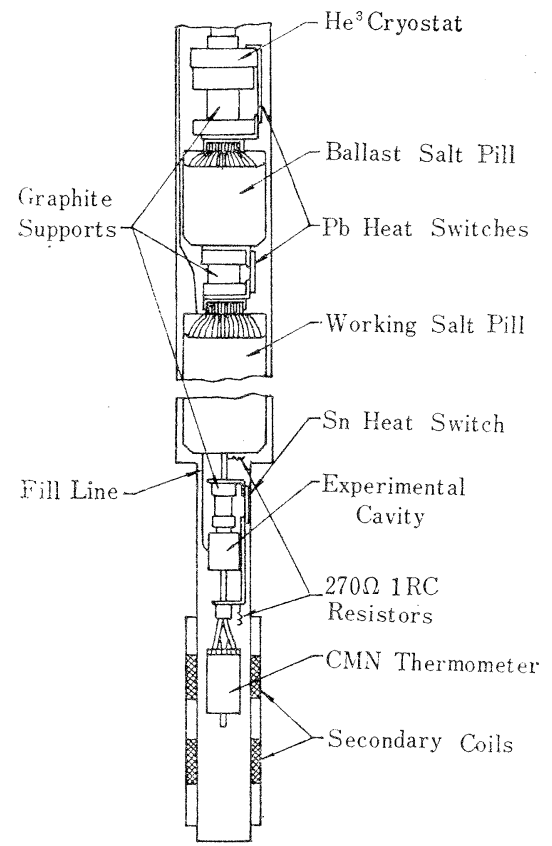

(a) 全体図
グリースを用いて，固定してしまう方法をとる。グラ ファイトの熱伝導はこの温度領域では非常に小さい83 ので, これ芷通しての温度ドリフトは無視出来る。

$0.04 \sim 0.1^{\circ} \mathrm{K}$ 附近まで, 温度ドリフトは温度上昇の 方向で $0.5 \mathrm{erg} / \mathrm{min}$ 程度である。

(iv) その他

温度計には Speer $\left(100 \Omega \frac{1}{2} W\right)$ カーボン扱礼を用い るが抵抗での熱の発生は $10^{-13} \mathrm{~W}$ 程度に和さえる必要 がある。

試料の冷却には $\mathrm{He}^{3}-\mathrm{He}^{4}$ mixing chamber との 間に超伝導スイッチ $\left(\mathrm{Sn} . \mathrm{A} / \mathrm{l} \simeq 10^{-4} \mathrm{~cm}\right)$ 老用いる。 このスイッチ然開く時, 不可逆性のため $2 \mathrm{erg}$ 程度の

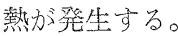

\section{4. 液体 $\mathrm{He}^{3}$ の比熱測定用クライオスタット}

液体 $\mathrm{He}^{3}$ の比熱は， $0.04^{\circ} \mathrm{K}$ 以下では大体 $24 \mathrm{~T}$ $\mathrm{j} / \mathrm{mole} \cdot \operatorname{deg}$ 程度の大きさであり，通常の比熱測定の 場合使用与る量效 c.c. すなわち 0.05 モル程度であ る。したがって闆題にする比熱の大きさは $1 \sim 10 \mathrm{mj} /$ deg 程度で, 金属試料の場合に比して $2 \sim 3$ 桁程大き W。

4.1 Fairbank らのクライオスタット9

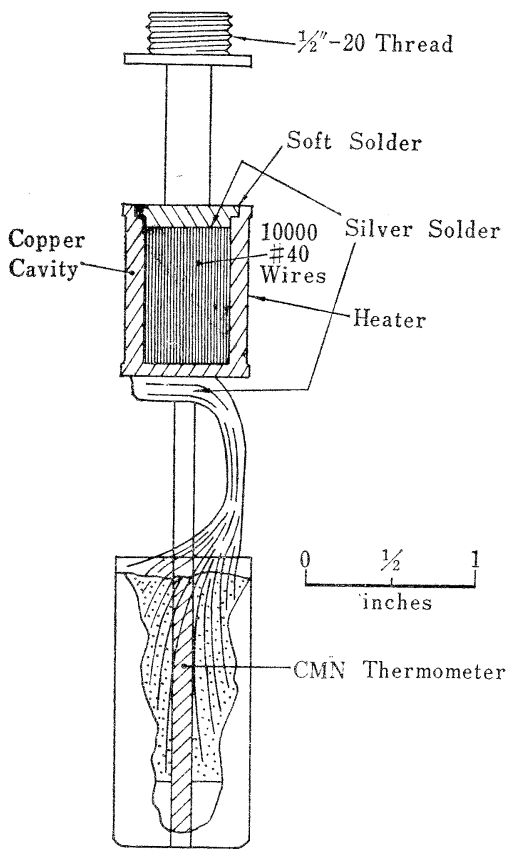

(b) 試料容器部分拡大困

図 4 Fairbank 達のクライオスタット

Vol. 4 No. 4 (1969) 


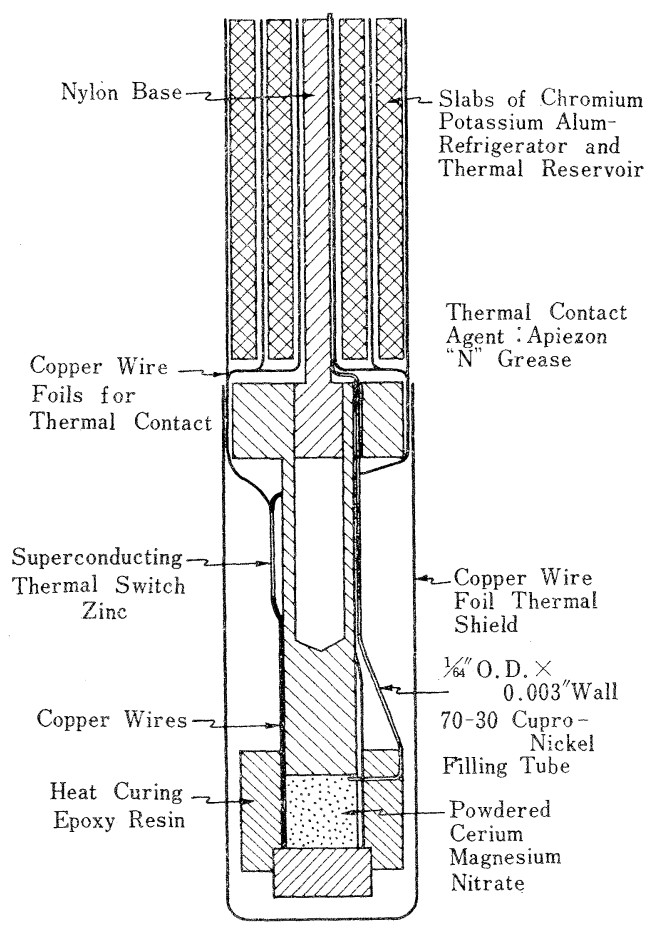

(a) 全 体図

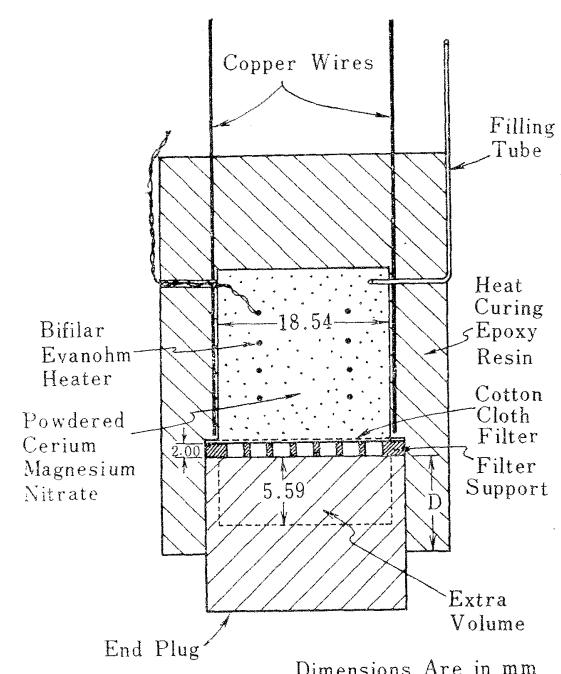

(b) 試料容器部分拡大図

図 5 Wheatley 達のクライオスタット

困4 にクライオスタットを示す。

(i) 测定温度領域

$$
0.3 \sim 0.054^{\circ} \mathrm{K}
$$

(ii) 冷却・断熱

$0.4^{\circ} \mathrm{K}$ までは $\mathrm{He}^{3}$ 浴で泠し, それ以下は $\mathrm{Cr}_{2}\left(\mathrm{SO}_{4}\right)_{3}$ • $\left(\mathrm{CH}_{3} \mathrm{NH}_{3}\right)_{2} \mathrm{SO}_{4} \cdot 24 \mathrm{H}_{2} \mathrm{O}$ の断熱消磁在用いる。塩の 使用量 $150 \mathrm{~g}$ 。塩は一万本の銅線 $(0.003$ - in $\phi)$ と共 にナイロン容器につめる。

試料の冷却には超伝導スイッチ $(\mathrm{Sn})$ を学用いる。 0.03 モルの液体 $\mathrm{He}^{3}$ 在最低温度に泠却可るのに 1 〜 2 時間要する。

(iii) その他

試料容器，塩などの支持にはグラファイトを使用す $3^{8)}$ 。

Heat leak $6 \sim 30 \mathrm{erg} / \mathrm{min}$ 程度である。温度計と して CMN を $10 \mathrm{~g}$ 用いている。

\subsection{Wheatley らのクライオスタット10}

図 5 にクライオスタットを示す。

(i) 測定温度領域

$0.004 \sim 0.15^{\circ} \mathrm{K}$

\section{(ii) 冷却・断熱}

$\mathrm{Cr}_{2}\left(\mathrm{SO}_{4}\right)_{2} \cdot \mathrm{K}_{2} \mathrm{SO}_{4} \cdot 24 \mathrm{H}_{2} \mathrm{O}$, 使用量 $100 \sim 250 \mathrm{~g}$ 。試料 容器との間は，千本の銅線 $(0.08 \mathrm{~mm} \phi)$ で結び間に 超伝導スイッチ $\left(\mathrm{Zn} \mathrm{A} / 1 \simeq 10^{-1}\right)$ をいれる。

$0.03^{\circ} \mathrm{K}$ 以下では熱スイッチは必要でなく $\mathrm{He}^{3}$ と容 器壁との間の熱抵抗で比熱測定に充分な断熱状態を得 るととが出来る。

(iii) その他

試料容器，塩の支持にナイロン进使用。Heat leak は $1.5 \mathrm{erg} / \mathrm{min}$ 程度。温度計として CMN の粉末 $(100 \sim 200 \mu) 6.5 \mathrm{~g}$ 在用い, 液体 $\mathrm{He}^{3}$ の中に浸して いる。試料セルはエポキシ系樹脂で作られ ${ }^{11)}$, 容積を 変化させて, 試料の量它変えるととにより, 容器 $\mathrm{CMN}$ 扎よびヒ一ターの比熱孝差し引く。ての addenda の 比熱は $0.03^{\circ} \mathrm{K}$ 以上では無視出来る。

\section{5. $\mathrm{CMN}$}

単結晶 CMN は $6 \mathrm{~m}^{\circ} \mathrm{K}$ まで Curie law 亿従う ${ }^{12)}$ とされている, $\mathrm{T}_{\mathrm{S}}{ }^{*}=\mathrm{T}\left(\mathrm{T}_{\mathrm{s}}{ }^{*}\right.$; 単結晶球状 CMN の magnetic temperature, $\mathrm{T}$; 熱力学的温度)。また, 
液体 $\mathrm{He}^{3}$ の自己拡散係数吕，粉末 CMN 孝筒状に 固为飞温度計芭使用した場合, $\mathrm{T}^{*}=2 \sim 3 \mathrm{~m}^{\circ} \mathrm{K}$ 程度ま で，1/T*-2 亿比例するという実験事害汃ら，乙の粉 末 CMN 丵用いた場合, $2 \sim 3 \mathrm{~m}^{\circ} \mathrm{K}$ でのTからのず

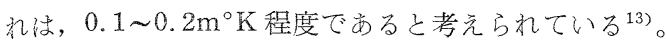

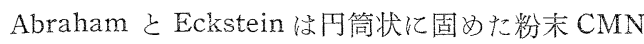
の比熱測定の結果加ら， $\mathrm{T}=\mathrm{T}_{\mathrm{s}}{ }^{*}=\mathrm{T}^{*}+\Delta$ 亿打いて $\Delta=1.7 \mathrm{~m}^{\circ} \mathrm{K}$ という大きな形状補正を結論した ${ }^{14)}$ (測 定温度領域 $3.86 \sim 35.25 \mathrm{~m}^{\circ} \mathrm{K}$ )。

しが, W の臨界磁場の測定と B.C.S の対応状態 ${ }^{14)}$ の法則との比較办 ら ${ }^{15)}$, 形状補正 $\Delta$ は $0.2 \sim 0.3 \mathrm{~m}^{\circ} \mathrm{K}$ 程度であるととが結論される。

A. C. Mota ${ }^{16)}$ らは，液体 $\mathrm{He}^{3}$ 和上び希薄 $\mathrm{He}^{3}-\mathrm{He}^{4}$ 溶液の比熱と, 測定容器の比熱 (大部分が温度計の粉 末 CMN によるものと考光られる）とを解析した結

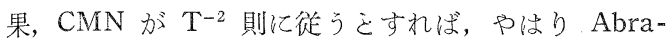
ham and Eckstein と同程度の, $\Delta=1.48 \mathrm{~m}^{\circ} \mathrm{K}$, 形状 補正が必要であるとと走した。結局, 液体 $\mathrm{He}^{3}$ 打 よび希薄 $\mathrm{He}^{3}-\mathrm{He}^{4}$ 溶液が, フェルミ流体論から予 言されない上うな性質を有するのか, それとも粉末の $\mathrm{CMN}$ の比熱が $6 \sim 15 \mathrm{~m}^{\circ} \mathrm{K}$ の範囲で $\mathrm{T}^{-2}$ 則加らは ずれるのか，どちらかというととになる。Abel と Wheatle ${ }^{17)}$ は, $10 \sim 38 \mathrm{~m}^{\circ} \mathrm{K}$ の範围で, 粉末 $\mathrm{CMN}$

（高さと直径が等しい長さの円筒状に固めたもの）と 単結晶球状 CMN $の$ magnetic temperature 在比較 測定して $\Delta=(0.46 \pm 0.05) \mathrm{m}^{\circ} \mathrm{K}$ 党得た。

したがって, Wheatley 達は, 少なくとも彼らが用 いている粉末 $\mathrm{CMN}$ 亿対しては, $6 \sim 15 \mathrm{~m}^{\circ} \mathrm{K}$ の領域 で $T^{-2}$ 則に合わ好と結論する。

単結晶 CMN についての Hudson と Kaeser ${ }^{12)} の$ 実験とのくいちがいが，単に粉末年結晶との差によ るのか，不純物のためなのか，他に何か原因がある。 和末解決である。

\section{参考文 献}

1) 大塚，佐藤：“熱温度測定と示差熱分析”（科学 技術社 1968） p. 1 「極低温に扣ける比熱測定の 現状」

2) N.E. Phillips: Phys. Rev. 114 (1959) 676 H. R. O'Neal and N. E. Phillips: Phys. Rev. 137 (1965) A 748
3) W. Reese and W. A. Steyert, Jr.: Rev. Sci. Instr. 33 (1962) 43

V.P. Peshkov and A. Y. Parshin: Soviet Physics JETP 21 (1965) 258

4) J.C. Ho, H.R. O'Neal and N.E. Phillips: Rev. Sci. Instr. 34 (1963) 782 マンガニン; 東京ワイヤー製作所(03-471-5131)

5) J. Ancsin and J. L. G. Lamarch: Rev. Sci. Instr. 38 (1967) 358

6) M. D. Daybell, W. A. Pratt, Jr. and W. A. Steyert: Phys, Rev. Letters 21 (1968) 353

7) J. C. Wheatley, O. E. Vilches and W. R. Abel: Physics 4 (1968) 1 「Principle and Methods of Dilution Refrigerator $\rfloor$

8) F. J. Shore, V. L. Sailor, H. Marshak and C. A. Reynolds: Rev. Sci. Instr. 31 (1960) 970 ピッチ，ボンド, グラファイト; 東海興商 (03-552-3701)

9) M. Strongin, G. O. Zimmerman and H. A. Fairbank: Phys. Rev. 128 (1962) 1983

10) A.C. Anderson, W. Reese and J. C. Wheatley: Phys. Rev. 130 (1963) 495

W. R. Abel, A.C. Anderson, W. C. Black and J. C. Wheatley: Phys. Rev. 147 (1966) 111

A. C. Mota, R. P. Platzeck, R. Rapp and J. C. Wheatley: Phys. Rev. 177 (1969) 266

J. C. Wheatley: "Quntum Fluid" (1966, North-Holland) p. 183

$\left\lceil\right.$ Experimental Properties of Liquid $\mathrm{He}^{3}$ at Very Low Temperatures」

11) J. C. Wheatley: Rev. Sci. Instr. 35 (1964) 765

W. R. Roach, J. C. Wheatley and A.C. Mota: Rev. Sci. Instr. 35 (1964) 634

G. L. Salinger and J. C. Wheatley: Rev. Sci. Instr. 32 (1961) 872

12) R. P. Hudson and R. S. Kaeser: Physics 3 (1967) 95

13) J.C. Wheatley: Ann. Acad. Sci. Fennical, Ser. AVI No. 210 (1966) 15

14) B. M. Abraham and Y. Eckstein: Phys, Rev. Letters 20 (1968) 649

15) W. C. Black: Phys. Rev. Letters 21 (1968) 28

16) A.C. Mota, R. P. Platzeck, R. Rapp and J. C. Wheatley: Phys. Rev. 177 (1969) 266

17) W. R. Abel and J. C. Wheatley: Phys. Rev. Letters 21 (1968) 597 